\title{
Investigation of luminescent Eu-doped sesquioxides Ln2O3 (Ln = In, c, Y, La, Gd, Lu) and some mixed oxides by 151Eu Mössbauer spectroscopy
}

\section{Citation for published version (APA):}

Hintzen, H. T. J. M., \& Noort, van, H. M. (1988). Investigation of luminescent Eu-doped sesquioxides Ln2O3 (Ln $=$ In, C, Y, La, Gd, Lu) and some mixed oxides by 151Eu Mössbauer spectroscopy. Journal of Physics and Chemistry of Solids, 49(8), 873-881. https://doi.org/10.1016/0022-3697(88)90003-0

DOI:

10.1016/0022-3697(88)90003-0

Document status and date:

Published: 01/01/1988

\section{Document Version:}

Publisher's PDF, also known as Version of Record (includes final page, issue and volume numbers)

\section{Please check the document version of this publication:}

- A submitted manuscript is the version of the article upon submission and before peer-review. There can be important differences between the submitted version and the official published version of record. People interested in the research are advised to contact the author for the final version of the publication, or visit the DOI to the publisher's website.

- The final author version and the galley proof are versions of the publication after peer review.

- The final published version features the final layout of the paper including the volume, issue and page numbers.

Link to publication

\footnotetext{
General rights

- You may freely distribute the URL identifying the publication in the public portal. follow below link for the End User Agreement:

www.tue.nl/taverne

\section{Take down policy}

If you believe that this document breaches copyright please contact us at:

openaccess@tue.nl

providing details and we will investigate your claim.
}

Copyright and moral rights for the publications made accessible in the public portal are retained by the authors and/or other copyright owners and it is a condition of accessing publications that users recognise and abide by the legal requirements associated with these rights.

- Users may download and print one copy of any publication from the public portal for the purpose of private study or research.

- You may not further distribute the material or use it for any profit-making activity or commercial gain

If the publication is distributed under the terms of Article $25 \mathrm{fa}$ of the Dutch Copyright Act, indicated by the "Taverne" license above, please 


\title{
INVESTIGATION OF LUMINESCENT Eu-DOPED SESQUIOXIDES $\mathrm{Ln}_{2} \mathrm{O}_{3}(\mathrm{Ln}=\mathrm{In}, \mathrm{Sc}, \mathrm{Y}, \mathrm{La}, \mathrm{Gd}, \mathrm{Lu})$ AND SOME MIXED OXIDES BY ${ }^{151} \mathrm{Eu}$ MÖSSBAUER SPECTROSCOPY
}

\author{
H. T. HINTZEN and H. M. VAN NOORT \\ Philips Research Laboratories, P.O. Box $80.000,5600 \mathrm{JA}$ Eindhoven, The Netherlands
}

(Recetved 25 April 1987; accepted 8 July 1987)

\begin{abstract}
Luminescent Eu-doped sesquioxides $\mathrm{Ln}_{2} \mathrm{O}_{3}(\mathrm{Ln}=\mathrm{In}, \mathrm{Sc}, \mathrm{Y}, \mathrm{La}, \mathrm{Gd}, \mathrm{Lu})$ and some mixed oxides have been investigated with ${ }^{151}$ Eu Mössbauer spectroscopy. The spectra are interpreted by using crystallographic and luminescence data. Effects of Eu concentration. substitution and crystal structure on the isomer shift are discussed in terms of Eu-O distance, coordination number and covalency. For the compounds with the cubic modification, no preferential site occupation by $\mathrm{Eu}^{3+}$ ions on the two available crystallographic sites can be concluded.
\end{abstract}

Keywords: Mössbauer spectroscopy, europium, sesquioxides, phosphors, luminescence.

\section{INTRODUCTION}

The element Eu can show efficient luminescence when it is incorporated in host lattices in its divalent $\left(\mathrm{Eu}^{2+}\right)$ or trivalent $\left(\mathrm{Eu}^{3+}\right)$ state [1]. Besides valency, the luminescence properties are strongly dependent on the local chemical environment of the activator ion, such as coordination number, site symmetry and bond character. These parameters can be studied with ${ }^{151}$ Eu Mössbauer spectroscopy, as has been shown for $\mathrm{LaMgAl} \mathrm{I}_{11} \mathrm{O}_{19}: \mathrm{Eu}$ (determination of the relative concentration of $\mathrm{Eu}^{2+}$ and $\mathrm{Eu}^{3+}$ ions [2]) and $\mathrm{Y}_{2} \mathrm{WO}_{6}: \mathrm{Eu}$ (measurement of the relative occupation of the three available yttrium sites by $\mathrm{Eu}^{3+}$ ions [3]). The most relevant parameter that can be obtained from the Mössbauer spectra is the value of the isomer shift, which is a measure of the $s$-electron density at the Eu nucleus [4]. An increase of the $s$-electron density, as a consequence of increasing coordination number, decreasing $\mathrm{Eu}-\mathrm{O}$ distance or increasing covalency, will result in an increase of the isomer shift.

Here we present the results of a study of Eu-doped sesquioxides $\mathrm{Ln}_{2} \mathrm{O}_{3}(\mathrm{Ln}=\mathrm{In}, \mathrm{Sc}, \mathrm{Y}, \mathrm{La}, \mathrm{Gd}, \mathrm{Lu})$, and some mixed oxides. $\mathrm{Y}_{2} \mathrm{O}_{3}: \mathrm{Eu}$ is a very important material as it is used as the red-emitting phosphor in fluorescent lamps and colour television projection tubes. Some Mössbauer data for $\mathrm{Y}_{2} \mathrm{O}_{3}$ : Eu have already been published in [5]. The complete series of Eu-doped sesquioxides $\mathrm{Ln}_{2} \mathrm{O}_{3}(\mathrm{Ln}=\mathrm{In}, \mathrm{Sc}, \mathrm{Y}, \mathrm{La}$, $\mathrm{Gd}, \mathrm{Lu}$ ) offers the opportunity to study the influence of the structure on the Mössbauer spectra, because in this series three different crystallographic modifications are found.

\section{DESCRIPTION OF THE} CRYSTALLOGRAPHIC MODIFICATIONS

The lanthanide sesquioxides with general formula $\mathrm{Ln}_{2} \mathrm{O}_{3}$ show many polymorphic forms. At atmos- pheric pressure, below $2000^{\circ} \mathrm{C}$, cubic, monoclinic and hexagonal modifications are observed [6]. Table 1 summarizes the number of different crystallographic sites, the site symmetry and the coordination number for these three modifications.

The transition of the cubic to the monoclinic or the hexagonal modification is characterized by an increase of the coordination number and a lowering of the symmetry. The interrelationships between these structures and the relation with the cubic fluorite structure of $\mathrm{CeO}_{2}$ are dealt with in [6]. In $\mathrm{CeO}_{2}$ the $\mathrm{Ce}^{4+}$ ions are coordinated by eight $\mathrm{O}^{2-}$ ions, centered at the vertices of a cube. In cubic $\operatorname{Ln}_{2} \mathrm{O}_{3}$, one-fourth of the $\mathrm{O}^{2-}$ ions have been removed (leading to a six coordination of the $\mathrm{Ln}^{3+}$ ion). This occurs in two different ways, namely along one of the four body diagonals or along one of the twelve face diagonals of the cube, leading to a ratio of $1: 3$ between the number of different sites in the cubic $\mathrm{Ln}_{2} \mathrm{O}_{3}$ lattice. In the first case a symmetric crystallographic site results (point symmetry: $S_{6}$ or $C_{3}$ ), while the site in the second case has a lower symmetry (point symmetry: $\mathrm{C}_{2}$ ).

For the cubic modification the six $\mathrm{Ln}-\mathrm{O}$ distances of the $S_{6}$ site are equal, whereas those of the $C_{2}$ site can be subdivided into three groups of each two equal distances. The average distance, which is about the same for the $S_{6}$ and the $C_{2}$ site, is proportional to the lattice parameter $\langle a\rangle$ of the cubic lattice [7].

The relation of the monoclinic and hexagonal modifications with the fluorite structure is more difficult to elucidate briefly; they can be described as a stacking of $(\mathrm{LnO})_{n}^{n+}$ layers separated by planes of oxygen ions. These $(\mathrm{LnO})_{n}^{n+}$ layers are formed by a two-dimensional packing of $\left(\mathrm{OLn}_{4}\right)$ tetrahedra, leading to crystallographic sites with rather low symmetry (point symmetries: $\mathrm{C}_{\mathrm{s}}$ and $\mathrm{C}_{3 v}$ for the monoclinic and hexagonal modification, respectively). As a con- 
Table 1. Number of different crystallographic sites for the $\mathrm{Ln}$ ion in three modifications of the sesquioxides $\mathrm{Ln}_{2} \mathrm{O}_{3}$, together with site symmetry and coordination number of each site. Between brackets subgroups of oxygen ions with (for the monoclinic modification roughly) the same $\mathrm{Ln}-\mathrm{O}$ distance are indicated in the sequence of increasing $\mathrm{Ln}-\mathrm{O}$ distance

\begin{tabular}{lcll}
\hline $\begin{array}{l}\text { Crystallographic } \\
\text { modification }\end{array}$ & $\begin{array}{c}\text { Number of } \\
\text { Ln-sites }\end{array}$ & $\begin{array}{c}\text { Site symmetries } \\
\text { (point group) }\end{array}$ & \multicolumn{1}{c}{$\begin{array}{c}\text { Coordination } \\
\text { numbers }\end{array}$} \\
\hline Cubic & 2 & $\mathrm{C}_{2}, \mathrm{~S}_{6}\left(=\mathrm{C}_{3}\right)$ & $6(=2+2+2), 6$ \\
Monoclinic & 3 & $\mathrm{C}_{s}, \mathrm{C}_{s}, \mathrm{C}_{\mathrm{s}}$ & $7(=6+1), 7(=6+1), 7(=6+1)$ \\
Hexagonal & 1 & $\mathrm{C}_{3 v}$ & $7(=3+1+3)$ \\
\hline
\end{tabular}

sequence the $\mathrm{Ln}-\mathrm{O}$ bond inside the $(\mathrm{LnO})_{n}^{n+}$ layer should be considered as more covalent than the $\mathrm{Ln}-\mathrm{O}$ bond between the $(\mathrm{LnO})_{n}^{n+}$ layers and the oxygen layer. The three different $\mathrm{Ln}$ ions in the monoclinic modification are sevenfold coordinated: two coordination polyhedra can be considered as a trigonal prism with the seventh oxygen ion at a slightly larger distance, the third site as an octahedron with the seventh oxygen ion at a substantially larger distance. The sevenfold coordination of the $\mathrm{Ln}$ ion in the hexagonal modification consists of an octahedral group of oxygen ions (from which three are nearby and three more apart) with the seventh ion at an intermediate distance above one of the octahedron faces on the threefold axis.

In the series of lattices $\mathrm{Ln}_{2} \mathrm{O}_{3}(\mathrm{Ln}=\mathrm{In}, \mathrm{Sc}, \mathrm{Y}, \mathrm{La}$, $\mathrm{Eu}, \mathrm{Gd}, \mathrm{Lu})$ studied here, all these crystallographic modifications are encountered, structural data of which are given in Table 2 .

\section{EXPERIMENTAL SECTION}

\section{1.. Preparation of the powder samples}

A series of $\mathrm{Y}_{2} \mathrm{O}_{3}:$ Eu samples with various $\mathrm{Eu}$ concentrations $(1,5,10,25$ and $50 \mathrm{~mol} \% \mathrm{Eu}$ with respect to $\mathrm{Y}$ ) were prepared by milling the starting solid oxides $\mathrm{Y}_{2} \mathrm{O}_{3}\left(5 \mathrm{~N}\right.$, Rhône-Poulenc) and $\mathrm{Eu}_{2} \mathrm{O}_{3}$ ( $5 \mathrm{~N}$, Péchiney and Rhône-Poulenc) in the desired ratio, together with $\mathrm{NH}_{4} \mathrm{Cl}(10$ weight\%, P.A. Merck) as a fluxing agent, under hexane in an agate ball mill for $5 \mathrm{~h}$. Afterwards, the mixture was dried and fired in alundum crucibles in a Naber room

Table 2. Data concerning the crystallographic structure of the sesquioxides $\mathrm{Ln}_{2} \mathrm{O}_{3}(\mathrm{Ln}=\mathrm{In}, \mathrm{Sc}, \mathrm{Y}, \mathrm{La}, \mathrm{Eu}, \mathrm{Gd}, \mathrm{Lu})$. The data have been collected and deduced from different literature sources (see [7])

\begin{tabular}{lcccc}
\hline Lattice & $\begin{array}{c}\text { Crystallographic } \\
\text { modification }\end{array}$ & \multicolumn{3}{c}{$\begin{array}{c}\text { Average } \mathrm{Ln}-\mathrm{O} \\
\text { distance }(\AA) \text { for } \\
\text { the different }\end{array}$} \\
\cline { 3 - 6 } & cutes \\
\hline $\mathrm{In}_{2} \mathrm{O}_{3}$ & cubic & 2.18 & 2.18 & 3 \\
$\mathrm{Sc}_{2} \mathrm{O}_{3}$ & cubic & 2.11 & 2.12 & \\
$\mathrm{Y}_{2} \mathrm{O}_{3}$ & cubic & 2.28 & 2.29 & \\
$\mathrm{La}_{2} \mathrm{O}_{3}$ & hexagonal & 2.54 & & \\
$\mathrm{Eu}_{2} \mathrm{O}_{3}$ & cubic & 2.34 & 2.34 & \\
$\mathrm{Eu}_{2} \mathrm{O}_{3}$ & monoclinic & 2.41 & 2.43 & 2.47 \\
$\mathrm{Gd}_{2} \mathrm{O}_{3}$ & cubic & 2.33 & 2.33 & \\
$\mathrm{Gd}_{2} \mathrm{O}_{3}$ & monoclinic & 2.39 & 2.41 & 2.46 \\
$\mathrm{Lu}_{2} \mathrm{O}_{3}$ & cubic & 2.24 & 2.24 & \\
\hline
\end{tabular}

furnace at $1500^{\circ} \mathrm{C}$ in air for $3 \mathrm{~h}$. Commercial materials $\mathrm{Y}_{2} \mathrm{O}_{3}$ : Eu with 3 and $5 \mathrm{~mol} \%$ Eu were prepared in a similar way at higher firing temperatures.

Two $\mathrm{Y}_{2} \mathrm{O}_{3}: \mathrm{Eu}$ samples with $5 \mathrm{~mol} \% \mathrm{Eu}$ were prepared in different ways: (1) Mixing solid oxides as described above and firing without a fluxing agent at $1200^{\circ} \mathrm{C}$; (2) Mixing solutions of $\mathrm{Y}\left(\mathrm{NO}_{3}\right)_{3}$ and $\mathrm{Eu}\left(\mathrm{NO}_{3}\right)_{3}$, coprecipitating the hydroxides, drying and firing without a fluxing agent at $900^{\circ} \mathrm{C}$. All the prepared $\mathrm{Y}_{2} \mathrm{O}_{3}: \mathrm{Eu}$ samples have the cubic modification.

For our measurements $\mathrm{Eu}_{2} \mathrm{O}_{3}$ was prepared in two different ways: (1) Firing the starting oxide $\mathrm{Eu}_{2} \mathrm{O}_{3}$ with $\mathrm{NH}_{4} \mathrm{Cl}$ as a fluxing agent; (2) Starting with an $\mathrm{Eu}\left(\mathrm{NO}_{3}\right)_{3}$ solution, precipitating $\mathrm{Eu}(\mathrm{OH})_{3}$, drying and firing without fluxing agent. The cubic and monoclinic modification of $\mathrm{Eu}_{2} \mathrm{O}_{3}$ were obtained at firing temperatures of 800 and $1500^{\circ} \mathrm{C}$, respectively.

The mixed oxides $(\mathrm{Y}, \mathrm{Ln})_{2} \mathrm{O}_{3}: \mathrm{Eu}(\mathrm{Ln}=\mathrm{In}, \mathrm{La}$, $\mathrm{Gd})$ and the other sesquioxides $\mathrm{Ln}_{2} \mathrm{O}_{3}: \mathrm{Eu}(\mathrm{Ln}=\mathrm{In}$, $\mathrm{Sc}, \mathrm{La}, \mathrm{Gd}, \mathrm{Lu})$ were prepared for only one Eu concentration of $5 \mathrm{~mol} \%$ using the same method as described above for the scries $\mathrm{Y}_{2} \mathrm{O}_{3}$ : Eu samples, starting with $\mathrm{In}_{2} \mathrm{O}_{3}$ (5N5, Billiton), $\mathrm{Sc}_{2} \mathrm{O}_{3}$ (4N, Reacton), $\mathrm{La}_{2} \mathrm{O}_{3} \cdot x \mathrm{H}_{2} \mathrm{O}$ (5N, Rare Earth Products), $\mathrm{Gd}_{2} \mathrm{O}_{3}\left(5 \mathrm{~N}\right.$, Rare Earth Products) and $\mathrm{Lu}_{2} \mathrm{O}_{3}(4 \mathrm{~N}$, Michigan Chemical Corporation). Firing was carried out at $1500^{\circ} \mathrm{C}$ (except for the $(\mathrm{Y}, \mathrm{Gd})_{2} \mathrm{O}_{3}$ : Eu compounds at $1300^{\circ} \mathrm{C}$ ).

In this way the cubic modification was formed, except for $\mathrm{La}_{2} \mathrm{O}_{3}: \mathrm{Eu}$ (hexagonal modification), $\mathrm{Gd}_{2} \mathrm{O}_{3}$ : Eu (monoclinic modification), $\mathrm{Y}_{0} \mathrm{In}_{10} \mathrm{Eu}_{01} \mathrm{O}_{3}$ (besides a solid solution with the cubic modification, a new compound was formed with a hexagonal modification), and $\mathrm{Y}_{09} \mathrm{La}_{10} \mathrm{Eu}_{0} \mathrm{O}_{3}$ (the main component was determined to have a monoclinic modification). To obtain $\mathrm{GdO}_{3}: \mathrm{Eu}$ with the cubic modification the firing temperature was taken as $1100^{\circ} \mathrm{C}$

The furnace was always allowed to cool down to room temperature before the samples were taken out. All the prepared powder samples were characterized by means of X-ray diffraction to check the presence of second phases and to determine the lattice parameters.

\subsection{Measurement of the Mössbauer spectra}

The ${ }^{151}$ Eu Mössbauer spectra were recorded in transmission using a conventional constant acceler- 

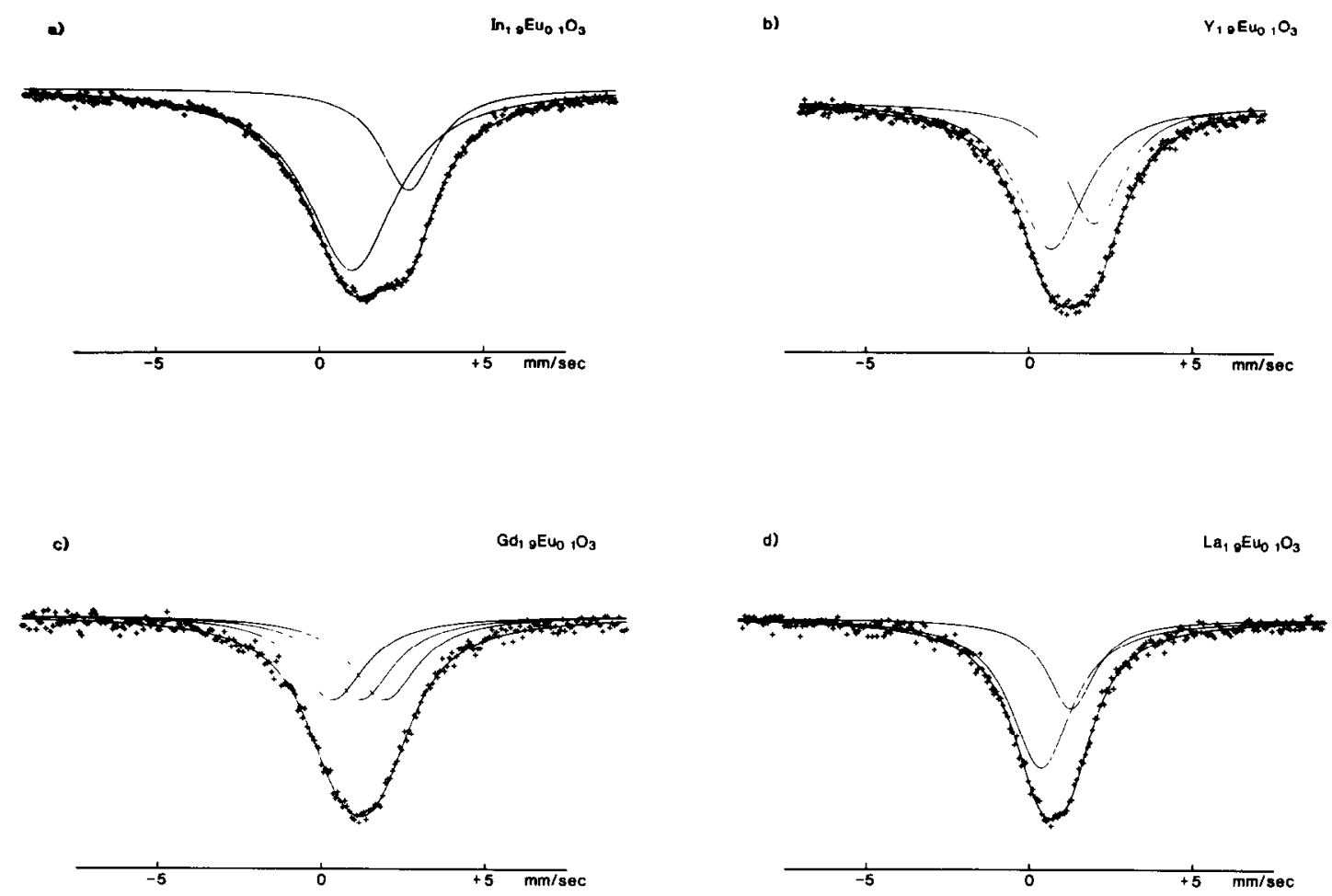

Fig. 1. The ${ }^{151} \mathrm{Eu}$ Mössbauer spectra of (a) cubic $\operatorname{In}_{19} \mathrm{Eu}_{01} \mathrm{O}_{3}$, (b) cubic $\mathrm{Y}_{19} \mathrm{Eu}_{01} \mathrm{O}_{3}$, (c) monoclinic $\mathrm{Gd}_{19} \mathrm{Eu}_{01} \mathrm{O}_{3}$ and (d) (partly hydrolysed) hexagonal $\mathrm{La}_{19} \mathrm{Eu}_{01} \mathrm{O}_{3}$.

ation spectrometer with a $200 \mathrm{mCi}{ }^{151} \mathrm{Sm}$ in $\mathrm{SmF}_{3}$ source. A proportional counter with $3 \% \mathrm{CO}_{2}$ in $\mathrm{Xe}$ was used to detect the $\gamma$-rays.

All measurements were performed at room temperature. Isomer shifts were calibrated against $\mathrm{EuF}_{3}$ and the velocity was calibrated with a ${ }^{57} \mathrm{Co}$ in $\mathrm{Pd}$ source and an $\alpha$-iron foil. The thickness of all samples was taken as $70 \mathrm{mg} \mathrm{cm}^{-2}$, but for $\mathrm{Eu}_{2} \mathrm{O}_{3}$ an amount of $30 \mathrm{mg} \mathrm{cm}^{-2}$ was taken. Each sample was measured during one week.

After firing the $\mathrm{La}_{2} \mathrm{O}_{3}$ : Eu sample it was immediately stored under dry nitrogen in a plastic bag to prevent hydrolysis as far as possible during the measurement of the Mössbauer spectrum.

\section{RESULTS}

The observed Mössbauer spectra of Eu-doped cubic $\operatorname{In}_{2} \mathrm{O}_{3}$ and $\mathrm{Y}_{2} \mathrm{O}_{3}$, monoclinic $\mathrm{Gd}_{2} \mathrm{O}_{3}$ and hexagonal $\mathrm{La}_{2} \mathrm{O}_{3}$ are shown in Fig. 1. No signal at about $-14 \mathrm{~mm} \mathrm{~s}^{-1}$ originating from $\mathrm{Eu}^{2+}$ ions was observed. The spectrum of $\operatorname{In}_{19} \mathrm{Eu}_{01} \mathrm{O}_{3}$ can clearly be decomposed into two Lorentzian lines (see Fig. 1(a)), which is also the case with $\mathrm{Sc}_{19} \mathrm{Eu}_{01} \mathrm{O}_{3}$. The two lines are attributed to $\mathrm{Eu}^{3+}$ ions substituted on the two available crystallographic sites in the cubic host lattice. To our knowledge this is the first time that the two subspectra belonging to $\mathrm{Eu}^{3+}$ ions at two different sites in this type of compound could be resolved.
In all other spectra of the Eu-doped sesquioxides with the cubic modification, the two components are not observable (see e.g. Fig. 1(b) for $\mathrm{Y}_{2} \mathrm{O}_{3}: E u$ ). We nevertheless fitted these spectra with two Lorentzian lines because luminescence measurements on $\mathrm{Y}_{2} \mathrm{O}_{3}: \mathrm{Eu}$ $[8-10], \mathrm{Gd}_{2} \mathrm{O}_{3}: \mathrm{Eu}[8,10]$ and $\mathrm{Lu}_{2} \mathrm{O}_{3}: \mathrm{Eu}[10]$ with the cubic modification give evidence of emission of $\mathrm{Eu}^{3+}$ ions on both crystallographic sites.

The Mössbauer spectrum of $\mathrm{Gd}_{1.9} \mathrm{Eu}_{0.1} \mathrm{O}_{3}$ with the monoclinic modification was fitted with three Lorentzian lines (see Fig. 1(c)), since there are three crystallographic sites in this structure and it is known from luminescence measurements that every position is occupied by $\mathrm{Eu}^{3+}$ ions [11].

The Mössbauer spectrum of partly hydrolysed $\mathrm{La}_{1}, \mathrm{Eu}_{0} \mathrm{O}_{3}$ with the hexagonal modification was fitted with two Lorentzian lines (see Fig. 1(d)). One line was attributed to $\mathrm{La}(\mathrm{OH})_{3}: \mathrm{Eu}$ which is inevitably formed after hydrolysis of $\mathrm{La}_{2} \mathrm{O}_{3}: \mathrm{Eu}$ despite the storage in a plastic bag and whose presence was demonstrated by X-ray diffraction measurements. The second Lorentzian was attributed to $\mathrm{Eu}^{3+}$ ions on the single available crystallographic site in the hexagonal modification, the luminescence of which has indeed been observed [12].

In the next section we will discuss the results of the fit of all spectra in more detail. The data obtained from the fit of the Mössbauer spectra of the different sesquioxides $\mathrm{Ln}_{1,} \mathrm{E}_{0,} \mathrm{O}_{3}(\mathrm{Ln}=\mathrm{In}, \mathrm{Sc}, \mathrm{Y}, \mathrm{La}, \mathrm{Gd}, \mathrm{Lu})$ and $\mathrm{Eu}_{2} \mathrm{O}_{3}$ are listed in Table 3 . 
Table 3. Total isomer shift and isomer shifts of the subspectra concerning the sesquioxides $\operatorname{Ln}_{19} \mathrm{Eu}_{0} \mathrm{O}_{3}$ $(\mathrm{Ln}=\mathrm{In}, \mathrm{Sc}, \mathrm{Y}, \mathrm{La}, \mathrm{Gd}, \mathrm{Lu})$ with three different crystallographic modifications. When more data are available, average values are given. As reference, the data of $\mathrm{Eu}_{2} \mathrm{O}_{3}$ with the cubic and monoclinic modification are also given

\begin{tabular}{|c|c|c|c|c|c|c|c|c|}
\hline \multirow[b]{2}{*}{ Compound } & \multirow{2}{*}{$\begin{array}{c}\text { Crystallographic } \\
\text { modification }\end{array}$} & \multirow{2}{*}{$\begin{array}{c}\text { Total } \\
\text { isomer } \\
\text { shifn } \\
\left(\mathrm{mm} \mathrm{s}^{-\mathrm{E}}\right)\end{array}$} & \multicolumn{3}{|c|}{$\begin{array}{c}\text { Isomer shift } \\
\left(\mathrm{mm} \mathrm{s}^{-3}\right)\end{array}$} & \multicolumn{3}{|c|}{$\begin{array}{l}\text { Linewidth } \\
\left(\mathrm{mm} \mathrm{s}^{-1}\right)\end{array}$} \\
\hline & & & 1 & 2 & 3 & 1 & 2 & 3 \\
\hline $\mathrm{In}_{1,9} \mathrm{Eu}_{0,} \mathrm{O}_{7}$ & cubic & 1.38 & 0.91 & 2.61 & & 3.13 & 1.91 & \\
\hline $\mathrm{Sc}_{1.9} \mathrm{Eu}_{0} \mathrm{O}_{3}$ & cubic & 1.27 & 0.70 & 2.59 & & 3.19 & 2.54 & \\
\hline $\mathrm{Y}_{19} \mathrm{Eu}_{0}, \mathrm{O}_{3}$ & cubic & 1.12 & 0.60 & 1.85 & & 2.45 & 2.10 & \\
\hline $\mathrm{La}_{1}, \mathrm{Eu}_{0}, \mathrm{O}_{3}$ & hexagonal & 0.60 & 0.344 & 1.20 & & $2.15 t$ & 1.69 & \\
\hline $\mathrm{Eu}_{2} \mathrm{O}_{3}$ & cubic & 0.88 & 0.43 & 1.56 & & $2.90^{\circ}$ & 2.63 & \\
\hline $\mathrm{Eu}_{2} \mathrm{O}_{3}$ & monoclinic & 0.99 & 0.12 & 1.02 & 1.92 & 2.57 & 2.24 & 2.57 \\
\hline $\mathrm{Gd}_{1}, \mathrm{Eu}_{0} \mathrm{O}_{3}$ & cubic & 1,05 & 0.58 & 1.76 & & 2.58 & 2.14 & \\
\hline $\mathrm{Gd}_{1}, \mathrm{Eu}_{0}, \mathrm{O}_{3}$ & monoclinic & 1.08 & 0.35 & 1.08 & 1.81 & 2.41 & 2.39 & 2.19 \\
\hline $\mathrm{Lu}_{1}, \mathrm{Eu}_{0} \mathrm{O}_{3}$ & cubic & 1.35 & 0.82 & 2.20 & & 2.65 & 2.18 & \\
\hline
\end{tabular}

† Signal of $\mathrm{La}_{19} \mathrm{Fu}_{01}(\mathrm{OH})_{3}$.

\section{DISCUSSION}

\subsection{Cubic modification}

5.1.1. Infuence of fitting procedure. If we thit the spectra of $\mathrm{In}_{19} \mathrm{Eu}_{0.1} \mathrm{O}_{3}$ (see Fig. $1(\mathrm{a})$ ) and $\mathrm{Sc}_{19} \mathrm{Eu}_{01} \mathrm{O}_{3}$ (which resembles that of $\mathrm{In}_{1}, \mathrm{Eu}_{0} \mathrm{O}_{3}$ ) with two Lorentzian lines we obtain an integrated intensity ratio for the two lines of almost 1:3, in agreement with the expectations from crystallographic data when the $\mathrm{Eu}^{3+}$ ions substitute randomly on the two different sites.

The spectra of the other cubic compounds were also fitted with two Lorentzian lines in two different ways: first with an intensity ratio which was kept fixed at 1:3, and secondly with no fixed intensity ratio. Fitting the spectra with a free intensity ratio gave no improvement compared with the fixed intensity ratio of $1: 3$.

In all figures we have plotted the isomer shift of the total line, since this parameter is somewhat more accurate than the isomer shift of the two components (for the cubic modification). However, both components show the same tendencies as the isomer shift of the total line. In all cases the total isomer shift is the weighted average of the isomer shifts of the components in which the line is decomposed.

Finally we checked whether the spectra could be fitted with a single Lorentzian line which is a little broadened by a quadrupole interaction. For $\mathrm{Eu}$ Mössbauer spectra it is well known that quadrupole interaction can give rise to an asymmetric total line-shape because of the large number of components resulting from the $I=7 / 2$ to $5 / 2$ transition [13]. We have used the method of Shenoy and Dunlap to fit the spectra [14]. In all cases we could fit the spectra with a single line with quadrupole splittings in the order of 3 to $5 \mathrm{~mm} \mathrm{~s}^{-1}$, which are reasonable values [15]. However, the quality of all fits improved by taking two Lorentzian lines without quadrupole splitting.

5.1.2. $\mathrm{Y}_{2} \mathrm{O}_{3}: \mathrm{Eu}$ (infuence of Eu concentration and preparation method). The isomer shift of the total line is $1.10-1.14 \mathrm{~mm} \mathrm{~s}^{-1}$ on average for $\mathrm{Y}_{2} \mathrm{O}_{3}:$ Eu samples with small Eu concentrations, which agrees quite well with the values from [5]. In Fig. 2 we have plotted the isomer shift of the total line as a function of the lattice parameter $\langle a\rangle$ (as measured on the same samples) for $\mathrm{Y}_{2-x} \mathrm{Eu}_{x} \mathrm{O}_{3}$.

An increasing lattice parameter will result in an increasing $\mathrm{Eu}-\mathrm{O}$ distance in a linear way (first paper of [7]) and in a decreasing isomer shift. At low Eu content the decrease of the isomer shift can be explained by the volume dependence of the isomer shift, as found by Kalvius et al. [16]. We have taken the following value $\mathrm{dIS} / \mathrm{d} \ln V=-5.3 \mathrm{~mm} \mathrm{~s}^{-1}$. The calculated volume dependence is indicated in Fig. 2 with a dashed line. For high Eu content the measured isomer shift is larger than the value one would expect on the basis of the volume dependence. The reason for this could be an increased covalency with increasing Eu content, as concluded for $\mathrm{Y}_{2} \mathrm{WO}_{6}: \mathrm{Eu}$ [3], because the ratio $S_{6} / C_{2}$ remains nearly constant (see below).

The line of the subspectrum with an average isomer shift of $0.6 \mathrm{~mm} \mathrm{~s}^{-1}$ and a relative intensity of 3 is attributed by us to $\mathrm{Eu}^{3+}$ ions substituted on the $\mathrm{C}_{2}$ site, the other line to the $\mathrm{S}_{6}$ site. Because the coordination number and average Eu-O distances are about the same, the larger isomer shift of $\mathrm{Eu}^{3+}$ ions at the $S_{6}$ site indicates an increased covalency, which is plausible on account of the symmetric environment with inversion symmetry. Independent support for a larger covalency at the $S_{6}$ site with respect to the $\mathrm{C}_{2}$ site comes from the observation that the $4 \mathrm{f}^{7} 5 \mathrm{~d}$ band of the $\mathrm{Tb}^{3+}$ ion in $\mathrm{Y}_{2} \mathrm{O}_{3}: \mathrm{Tb}$ has a lower energy for the $S_{6}$ site than for the $\mathrm{C}_{2}$ site [10].

Due to the less symmetric environment of the $\mathrm{C}_{2}$ site, a larger quadrupole splitting will be expected for $\mathrm{Eu}^{3+}$ ions substituted on the $\mathrm{C}_{2}$ site as compared with the $\mathrm{S}_{6}$ site. Moreover, six $\mathrm{Y}-\mathrm{O}$ distances are the same for the $S_{6}$ site, whereas in the case of the $C_{2}$ site there are three groups of significantly different distances [7]. We expect therefore a larger linewidth for the $C_{2}$ site than for the $S_{6}$ site, which has been observed.

Dulaney and Clifford have studied a large number 


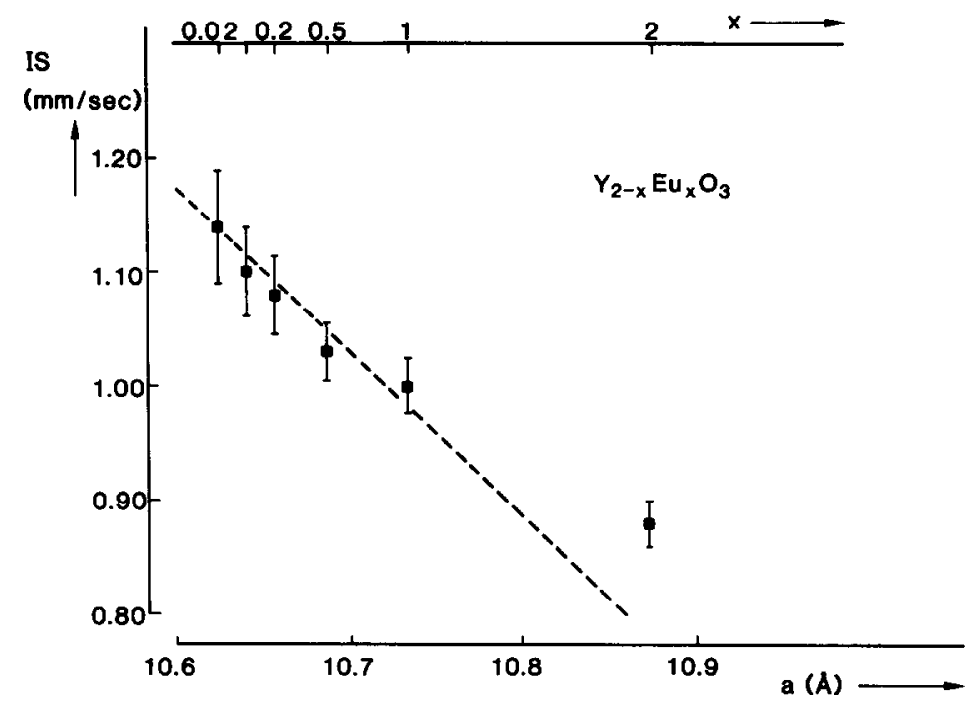

Fig. 2. The total isomer shift as a function of the measured lattice parameter $\langle a\rangle$ for a series of cubic $\mathrm{Y}_{2-x} \mathrm{Eu}_{x} \mathrm{O}_{3}$ samples. The dashed line indicates the volume dependence.

of mixed oxide structures and have observed the broadest total resonance lines of the Mössbauer spectra for the oxides with the presumed highest crystal symmetry [17] irrespective of the possibility of more than one crystallographic site. We assume, however, that within a certain crystal structure with different sites the Mössbauer line of $\mathrm{Eu}^{3+}$ ions on a specific site will be broader when the surroundings of the $\mathrm{Eu}^{3+}$ ion are less symmetric.

We did not observe a systematic relation between the relative intensities of the two lines with which the spectra were fitted and the Eu content, as is the casc for $\mathrm{Y}_{2} \mathrm{WO}_{6}$ : $\mathrm{Eu}$ [3].

Taking the uncertainty of the measurements into account, we cannot conclude that for a Eu content exceeding $1 \mathrm{~mol} \%$ the $\mathrm{Eu}^{3+}$ ions substitute in a preferential way on one of the two crystallographic sites. It is interesting to mention in this respect that Forest and Ban have found from reflection measurements that the distribution is approximately random [18]

The fact that we have never found an intensity ratio larger than 3 indicates that, when there is a slight difference in stability of $\mathrm{Eu}^{3+}$ ions incorporated on both sites, the most favourable position is the $S_{6}$ site with inversion symmetry.

As compared with the samples discussed until now (prepared from solid oxides with $\mathrm{NH}_{4} \mathrm{Cl}$ as a fluxing agent fired at $1500^{\circ} \mathrm{C}$ ), the $\mathrm{Y}_{19} \mathrm{Eu}_{01} \mathrm{O}_{3}$ compounds synthesised in totally different ways without fluxing agent [(1) solid oxides, $1200^{\circ} \mathrm{C}$; (2) coprecipitated material, $900^{\circ} \mathrm{C}$ ] did not show many differences, in contrast with luminescence measurements. The isomer shifts of the total line did not show any change, indicating roughly the same average local environment of the $\mathrm{Eu}^{3+}$ ions, independent of the preparation method. The width of the total line is slightly larger than the linewidth of the other $\mathrm{Y}_{2} \mathrm{O}_{3}$ : Eu samples. We feel that as a consequence of the less optimum preparation conditions for these samples there is a distribution of slightly different environments for both crystallographic sites, resulting in line broadening. The intensity ratio of the lines of the two subspectra is not changed.

This appears to be valid for the commercial phosphors as well, which for the rest gave results which were identical with the results of the samples prepared by us using $\mathrm{NH}_{4} \mathrm{Cl}$ as a fluxing agent.

Pappalardo and Hunt argue that the possibility of a preferential site occupation will not affect significantly the cmission brightness of $\mathrm{Y}_{2} \mathrm{O}_{3}: \mathrm{Eu}$, because of efficient energy transfer from $\mathrm{Eu}^{3+}$ ions on the $S_{6}$ site to $\mathrm{Eu}^{3+}$ ions on the $\mathrm{C}_{2}$ site [19]. However, they have not considered the influence of a preferential site occupation on the absorption, which also determines the emission brightness. The fact that we have not found a preferential site occupation indicates that this cannot be a possible explanation for the observed variation in emission brightness shown by different commercial phosphors [19].

5.1.3. (Y, Ln $)_{2} \mathrm{O}_{3}: \mathrm{Eu}(\mathrm{Ln}=\mathrm{In}, \mathrm{La}, \mathrm{Gd})$ and $\mathrm{Ln}_{2} \mathrm{O}_{3}: \mathrm{Eu}(\mathrm{Ln}=\mathrm{In}, \mathrm{Sc}, \mathrm{Gd}, \mathrm{Lu})$. In Fig. 3 we have plotted the isomer shift of the total line as a function of $x$ for the mixed oxides $\mathrm{Y}_{1.9-x} \mathrm{In}_{x} \mathrm{Eu}_{0,1} \mathrm{O}_{3}$, $\mathrm{Y}_{19-x} \mathrm{Gd}_{x} \mathrm{Eu}_{0} \mathrm{O}_{3}$ and $\mathrm{Y}_{19-x} \mathrm{La}_{x} \mathrm{Eu}_{0.1} \mathrm{O}_{3}$. It is clear that there is a strong dependence on $x$. This can be qualitatively explained if we consider the size of the lattice ions involved. If $Y$ ions are replaced by the smaller In ions the lattice parameter will decrease a little and therefore the average $\mathrm{Eu}-\mathrm{O}$ distance will also decrease. This gives rise to an increased electron density at the Eu nucleus and to a larger isomer shift On the other hand if the $Y$ ions are replaced by the larger $\mathrm{La}$ or $\mathrm{Gd}$ ions the lattice will expand a little, the average $\mathrm{Eu}-\mathrm{O}$ distance will increase and the isomer shift will decrease.

The difference in size between $\mathrm{Y}$ and $\mathrm{La}$ is larger 


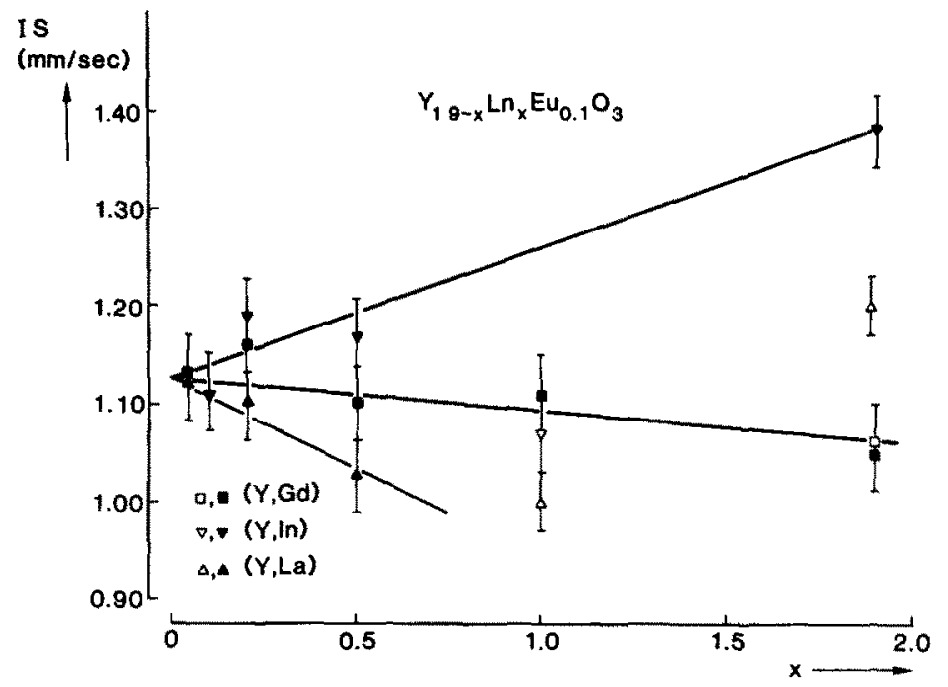

Fig. 3. The total isomer shift as a function of $x$ for the series $Y_{19-x} \ln _{x} E u_{01} \mathrm{O}_{3}, Y_{19-x} \mathrm{La}_{x} \mathrm{Eu}_{01} \mathrm{O}_{3}$ and $\mathrm{Y}_{19-x} \mathrm{Gd}_{x} \mathrm{Eu}_{01} \mathrm{O}_{3}$. Filled symbols refer to the oxides with the cubic modification.

than between $Y$ and $G d$ and therefore the change in isomer shift will be larger for $\mathrm{Y}_{19-x} \mathrm{La}_{x} \mathrm{Eu}_{01} \mathrm{O}_{3}$ than for $\mathrm{Y}_{19-x} \mathrm{Gd}_{x} \mathrm{Eu}_{01} \mathrm{O}_{3}$.

Some measurements do not fit into this picture. It concerns sesquioxides which do not have the cubic modification: much deviation was found for hexagonal $\mathrm{La}_{19} \mathrm{Eu}_{01} \mathrm{O}_{3}$ and $\mathrm{Y}_{09} \operatorname{In}_{10} \mathrm{Eu}_{01} \mathrm{O}_{3}$, and only a slight deviation for monoclinic $\mathrm{Gd}_{1} E_{u_{0}} \mathrm{O}_{3}$ and $\mathrm{Y}_{09} \mathrm{La}_{10} \mathrm{Eu}_{01} \mathrm{O}_{3}$.

It is remarkable that the signal-to-noise ratio was lower for the mixed oxides, due to a smaller Mössbauer fraction probably as a consequence of the larger number of different phonon energies which are available.

In Fig. 4 we have plotted the isomer shift of the total line as a function of the lattice parameter $\langle a\rangle$ for cubic $\mathrm{Ln}_{1}, \mathrm{Eu}_{0}, \mathrm{O}_{3}(\mathrm{Ln}=\mathrm{In}, \mathrm{Sc}, \mathrm{Gd}$ and $\mathrm{Lu})$. Also included are the data of Fig. 2: cubic $\mathrm{Y}_{2-x} \mathrm{Eu}_{x} \mathrm{O}_{3}$ and Fig. 3: cubic $Y_{19-x} \mathrm{Ln}_{x} \mathrm{Eu}_{0,} \mathrm{O}_{3},(\mathrm{Ln}=\mathrm{In}, \mathrm{La}$ and $\mathrm{Gd})$, now as a function of the lattice parameter $\langle a\rangle$. It is clear that there exists a relation between the lattice parameter $\langle a\rangle$ and the isomer shift.

Except for Sc, the isomer shift increases with decreasing lattice parameter. This can also bc explained by the volume dependence of the isomer shift, except for In. The calculated volume dependence is indicated in Fig. 4 by the dashed line.

It is obvious that the isomer shifts of $\operatorname{In}_{19} E_{u_{0}} \mathrm{O}_{3}$ and $\mathrm{Sc}_{19} \mathrm{Eu}_{01} \mathrm{O}_{3}$ are much smaller than one would expect on the basis of the volume dependence. It is questionable whether the simple relations describing the volume dependence of the isomer shift, which can

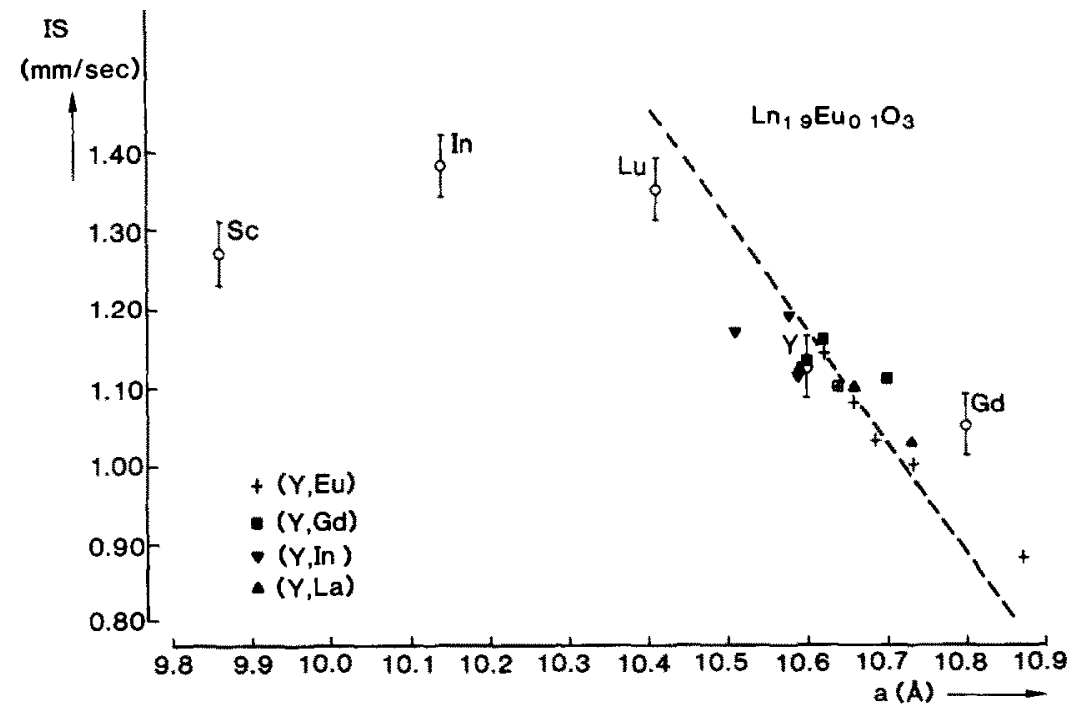

Fig. 4. The total isomer shift as a function of the measured lattice parameter $\langle a\rangle$ of the cubic lattice for $\mathrm{Y}_{2-x} \mathrm{Eu}_{\mathrm{x}} \mathrm{O}_{3}, \mathrm{Y}_{19-x} \mathrm{Ln}_{\mathrm{x}} \mathrm{Eu}_{0}, \mathrm{O}_{3}(\mathrm{Ln}=\mathrm{In}, \mathrm{La}, \mathrm{Gd})$ and $\mathrm{Ln}_{19} \mathrm{Eu}_{0}, \mathrm{O}_{3}(\mathrm{Ln}=\mathrm{In}, \mathrm{Sc}, \mathrm{Gd}, \mathrm{Lu})$. The dashed line indicates the volume dependence. 


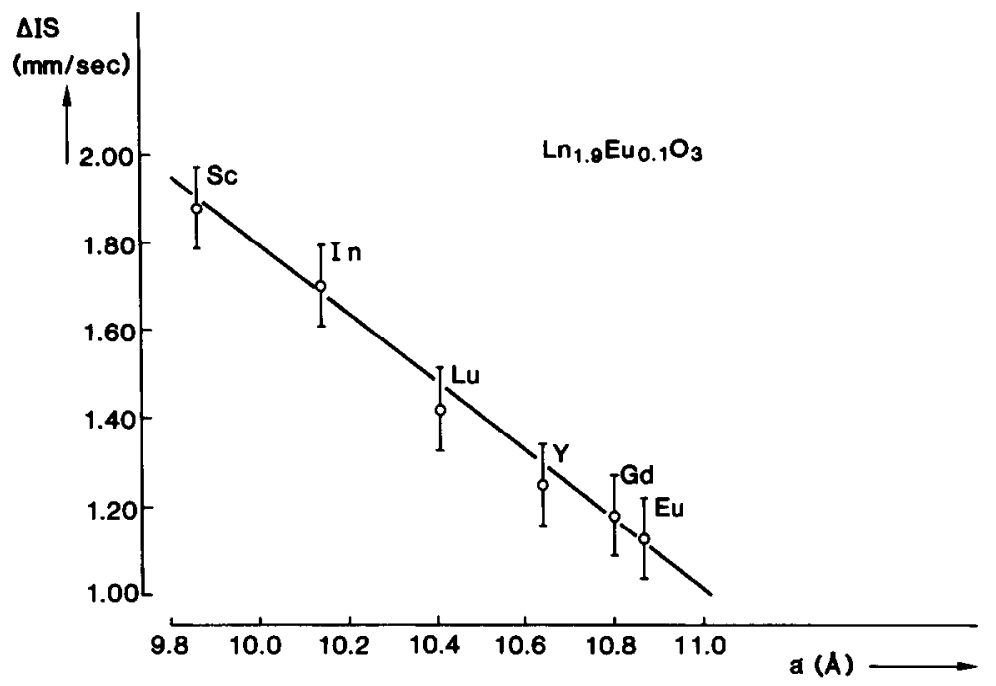

Fig. 5. The difference between the isomer shifts of $\mathrm{Eu}^{3+}$ ions on the $\mathrm{S}_{6}$ site and $\mathrm{C}_{2}$ site for cubic $\mathrm{Ln}_{1} \mathrm{Eu}_{0} \mathrm{O}_{3}$ $(\mathrm{Ln}=\mathrm{In}, \mathrm{Sc}, \mathrm{Y}, \mathrm{Gd}, \mathrm{Lu})$ and $\mathrm{Eu}_{2} \mathrm{O}_{3}$ as a function of the measured lattice parameter $\langle a\rangle$.

be found in the literature [16], are valid for volume changes of more than about $25 \%$. Several reasons can be put forward to explain this downward deviation. Sc, and especially In, are more electronegative than Eu, resulting in a lower $s$-electron density at the Eu nucleus and thus a smaller isomer shift. From the considerable difference between the ionic radius of the $\mathrm{Eu}^{3+}$ ion and that of the $\mathrm{In}^{3+}$, and especially of the $\mathrm{Sc}^{3+}$ ion, one expects considerable local distortions, which have been observed with luminescence measurements even in $\mathrm{Y}_{2} \mathrm{O}_{3}$ : Eu [20], resulting in less symmetric sites and thus a smaller isomer shift.

Some broadening of the Mössbauer spectrum is also ascribed to the local distortions. Moreover, in this situation of strongly oppressing oxygen ions, it is likely that penetration into the more inner orbitals of the $\mathrm{Eu}^{3+}$ ion takes place, leading to an electron donation into the $4 f$ orbitals resulting in a smaller isomer shift [21].

In Fig. 5 we have plotted the difference in isomer shift between the $S_{6}$ and $C_{2}$ sites as a function of the lattice parameter $\langle a\rangle$ for the cubic sesquioxides $\mathrm{Ln}_{1} \mathrm{Eu}_{0} \mathrm{O}_{3}(\mathrm{Ln}=\mathrm{In}, \mathrm{Sc}, \mathrm{Y}, \mathrm{Gd}, \mathrm{Lu})$ and $\mathrm{Eu}_{2} \mathrm{O}_{3}$. It is clear that this difference increases with decreasing lattice parameter.

A decrease of the lattice parameter will result in a decrease of the $\mathrm{Eu}-\mathrm{O}$ distance and in an increase of the electron density, which affects the $S_{6}$ site more than the $\mathrm{C}_{2}$ site. If we compare this difference in isomer shift with the isomer shift of the total line, it appears that the ratio between the two does not change very much over the whole series. The increasing difference makes it possible to distinguish clearly the $S_{6}$ and $C_{2}(v)$ sites in the spectra of $\mathrm{In}_{1.9} \mathrm{Eu}_{0.1} \mathrm{O}_{3}$ (see Fig. 1(a)) and $\mathrm{Sc}_{1,9} \mathrm{Eu}_{0.1} \mathrm{O}_{3}$.

\subsection{Monoclinic modification $\left(\mathrm{Gd}_{2} \mathrm{O}_{3}: \mathrm{Eu}\right)$}

In Fig. 1(c) we showed the Mössbauer spectrum of monoclinic $\mathrm{Gd}_{1}, \mathrm{Eu}_{0} \mathrm{O}_{3}$. The spectrum of mono- clinic $\mathrm{Eu}_{2} \mathrm{O}_{3}$ looks the same. The decrease of the isomer shift of $1.08 \mathrm{~mm} \mathrm{~s}^{-1}$ for monoclinic $\mathrm{Gd}_{19} \mathrm{Eu}_{01} \mathrm{O}_{3}$ to $0.99 \mathrm{~mm} \mathrm{~s}^{-1}$ for $\mathrm{Eu}_{2} \mathrm{O}_{3}$ can be fully explained by the volume dependence.

The isomer shift of the total line of the monoclinic modification is 0.03 and $0.11 \mathrm{~mm} \mathrm{~s}^{-1}$ larger than the cubic modification of $\mathrm{Gd}_{19} \mathrm{Eu}_{01} \mathrm{O}_{3}$ and $\mathrm{Eu}_{2} \mathrm{O}_{3}$, respectively.

Dulaney and Clifford measured only a small increase of $0.007 \mathrm{~mm} \mathrm{~s}^{-1}$ for cubic $\mathrm{Eu}_{2} \mathrm{O}_{3}$ as compared with monoclinic $\mathrm{Eu}_{2} \mathrm{O}_{3}$ [17], whereas Gerth et al., reported a change of $0.22 \mathrm{~mm} \mathrm{~s}^{-1}$ with respect to monoclinic $\mathrm{Eu}_{2} \mathrm{O}_{3}$ for an $\mathrm{Eu}_{2} \mathrm{O}_{3}$ material, whose modification is not given [22]. These differences can probably be attributed to a different thermal history of the samples, which has been reported to influence the isomer shift of $\mathrm{Eu}_{2} \mathrm{O}_{3}$ significantly [23].

The isomer shift of our monoclinic and also our cubic $\mathrm{Eu}_{2} \mathrm{O}_{3}$ did not show any dependence on the two preparation methods used.

The difference in isomer shift between the monoclinic and cubic structure is due to the different oxygen surroundings of the $\mathrm{Eu}^{3+}$ ions in the two crystallographic modifications.

We feel that the effect of larger average distances of six $\mathrm{Gd}-\mathrm{O}$ (and consequently $\mathrm{Eu}-\mathrm{O}$ ) bonds in the monoclinic modification as compared with the corresponding bonds in the cubic modification, can only partly be compensated by the seventh oxygen ion at a significantly larger distance. The total effect can only result in an increase of the isomer shift if we assume a considerable increase of covalency in the monoclinic modification. The larger difference in isomer shift between monoclinic and cubic $\mathrm{Eu}_{2} \mathrm{O}_{3}$ as compared with the corresponding $\mathrm{Gd}_{19} \mathrm{Eu}_{0.1} \mathrm{O}_{3}$ compounds also indicates a higher covalency contribution due to an increased Eu concentration.

The spectra of the monoclinic phases have been fitted with three Lorentzian lines with equal relative 
intensity (belonging to the $\mathrm{Eu}^{3+}$ ions incorporated on the three different crystallographic sites, as observed with luminescence measurements [11]). Fitting the spectra with different relative intensities gave no improvement. We therefore conclude that the $\mathrm{Eu}^{3+}$ ions are equally distributed over the three available sites in monoclinic $\mathrm{Gd}_{19} \mathrm{Eu}_{0} \mathrm{O}_{3}$.

Because all sites are sevenfold coordinated, a relation should exist between isomer shift and average $\mathrm{Eu}-\mathrm{O}$ distance. The smallest isomer shift of $0.35 \mathrm{~mm} \mathrm{~s}^{-1}$ is attributed to $\mathrm{Fu}^{3+}$ ions which are substituted on the site with the seventh oxygen ion far away (average distance $2.46 \AA$ ). The isomer shifts at 1.08 and $1.81 \mathrm{~mm} \mathrm{~s}^{1}$ are ascribed to $\mathrm{Eu}^{3+}$ ions on the sites with average $\mathrm{Gd}-\mathrm{O}$ (and thus roughly the same $\mathrm{Eu}-\mathrm{O}$ ) distances of 2.41 and $2.39 \AA$, respectively.

The situation is quite analogous to that in $\mathrm{Y}_{2} \mathrm{WO}_{6}: \mathrm{Eu}$ [3]. Despite the higher coordination number and shorter $\mathrm{Eu}-\mathrm{O}$ bonds in $\mathrm{Y}_{2} \mathrm{WO}_{6}: \mathrm{Eu}$, the isomer shifts of the three subspectra $(0.05,0.65$ and $1.25 \mathrm{~mm} \mathrm{~s}^{-1}$ ) are all smaller than the corresponding values for monoclinic $\mathrm{Gd}_{2} \mathrm{O}_{3}: \mathrm{Eu}$, indicating a large contribution of covalency effects in the latter compound

\subsection{Hexagonal modification $\left(\mathrm{La}_{2} \mathrm{O}_{3}: \mathrm{Eu}\right)$}

The Mössbauer spectrum of $\mathrm{La}_{19} \mathrm{Eu}_{0} \mathrm{O}_{3}$ is shown in Fig. 1(d). Since this material is rather hygroscopic, the compound $\mathrm{La}(\mathrm{OH})_{3}$ : Eu was formed during the measurement despite the storage in a plastic bag. This was confirmed by X-ray diffraction measurements. We therefore also measured the Mössbauer spectrum of pure $\mathrm{La}(\mathrm{OH})_{3}: \mathrm{Eu}$. This spectrum consists of a single line with an isomer shift of $0.34 \mathrm{~mm} \mathrm{~s}^{-1}$. The observed spectrum of partly hydrolysed $\mathrm{La}_{1.9} \mathrm{Eu}_{01} \mathrm{O}_{3}$ consists of two subspectra. The first at about $0.34 \mathrm{~mm} \mathrm{~s}^{-1}$, whose intensity increases with measuring time due to continuing hydrolysis, belongs clearly to $\mathrm{La}(\mathrm{OH})_{3}: \mathrm{Eu}$. The second subspectrum, belonging to $\mathrm{La}_{2} \mathrm{O}_{3}: \mathrm{Eu}$, can be fitted well with one Lorentzian line due to $\mathrm{Eu}^{3+}$ ions substituted on the only site available in this host lattice.

The isomer shift of $1.20 \mathrm{~mm} \mathrm{~s}^{-1}$ is somewhat higher than the value observed for the cubic modification with the largest $\mathrm{Ln}-\mathrm{O}$ distance. The three shortest bonds $(2.37 \AA)$ are even longer than in the most expanded cubic modification, the fourth oxygen ion is at $2.46 \AA$ and the remaining three at $2.73 \AA$. We therefore deduce an effect of increased covalency in hexagonal $\mathrm{La}_{19} \mathrm{Eu}_{01} \mathrm{O}_{3}$, as compared with the cubic modification, despite coordination of the $\mathrm{Eu}^{3+}$ ions with, in total, seven oxygen ions.

Because at the shortest $\mathrm{Ln}-\mathrm{O}$ distance only three oxygen ions are present in hexagonal $\mathrm{La}_{2} \mathrm{O}_{3}$ :Eu (at $2.37 \AA$ ), while in monoclinic $\mathrm{Gd}_{2} \mathrm{O}_{3}: E u$ the six nearest oxygens are at $2.35 \AA$, on the average, we have to assume an increased covalency effect in hexagonal $\mathrm{La}_{2} \mathrm{O}_{3}: \mathrm{Eu}$ as compared with monoclinic $\mathrm{Gd}_{2} \mathrm{O}_{3}: \mathrm{Eu}$.

\section{CONCLUSIONS}

In summary, with ${ }^{151} \mathrm{Eu}$ Mössbauer spectroscopy we have gained information concerning the site occupation and bonding of $\mathrm{Eu}^{3+}$ ions incorporated in sesquioxides $\mathrm{Ln}_{2} \mathrm{O}_{3}(\mathrm{Ln}=\mathrm{In}, \mathrm{Sc}, \mathrm{Y}, \mathrm{La}, \mathrm{Gd}, \mathrm{Lu})$ and some mixed oxides, by correlation with crystallographic and luminescence data.

We have shown that the dependence of the isomer shift on the lattice parameter $\langle a\rangle$ of the sesquioxides with the cubic modification can be described by the volume dependence for limited volume changes.

In the spectra of cubic $\operatorname{In}_{19}{E u_{01}}_{O_{3}} \mathrm{O}_{3} \mathrm{Sc}_{1} \mathrm{Eu}_{01} \mathrm{O}_{3}$ the two subspectra belonging to $\mathrm{Eu}^{3+}$ ions on the two different crystallographic sites are clearly resolved. The subspectrum with the highest isomer shift is ascribed to $\mathrm{Eu}^{3+}$ ions on the most symmetric site. There is no indication that the occupation of the two available sites in the cubic modification by $\mathrm{Eu}^{3+}$ ions is preferential, i.e. deviates from the expected $1: 3$ ratio.

The values of the isomer shift obtained for the monoclinic and hexagonal modification suggest an increased covalency with respect to the cubic modification, which is in accordance with structural data.

Acknowledgements - The authors are indebted to Mrs J. M. E. Baken for the preparation of the powder samples. Commercial $\mathrm{Y}_{2} \mathrm{O}_{3}$ : Eu phosphors were kindly supplied by the Philips Lighting Division. $\mathrm{Mr} \mathrm{C}$. Langereis is thanked for the X-ray diffraction measurements and for determining the lattice parameters. The authors would like to thank Dr Ir. C. J. M. Denissen for his help with the Mössbauer measurements.

\section{REFERENCES}

1. Blasse G. and Bril A., Philips Techn. Rev., 31, 304 (1970).

2. Tronc E., Saber D., Lejus A. M. and Vivien D., J. Less Common Met., 111, 321 (1985).

3. Van Noort H. M. and Popma T. J. A., Solid State Comm., 55, 77 (1985).

4. Bauminger E. R., Kalvius G. M. and Nowik I., Mössbauer Isomer Shifts (Edited by G. K. Shenoy and F. E. Wagner), p. 661. North-Holland, Amsterdam (1978).

5. Fraknóy-Kórós V., Gelencsér P., Czakó Nagy I. and Vértes A., Radiochem. Radioanal. Lett., 44, 337 (1980).

6. Eyring L., Handbook on the Physics and Chemistry of Rare Earths (Edited by K. A. Gschneidner $\mathrm{Jr}$ and L. Eyring), Vol. 3, Ch. 27, p. 337. North-Holland Publishing Company (1979).

7. O'Connor B. H. and Valentine T. M., Acta Cryst., B25, 2140 (1969); Faucher M. and Pannetier J., Acta Cryst., B36, 3209 (1980); Yakel H. L., Acta Cryst., B35, 564 (1979); Aldebert P. and Traverse J. P., Mater. Res. Bull., 14, 303 (1979); Wells A. F., Structural Inorganic Chemistry, fourth edition, p. 450. Oxford University Press (1975); Powder diffraction files of the JCPDS system.

8. Forest H. and Ban G., J. Electrochem. Soc., 116, 474 (1969).

9. Hunt R. B., Jr and Pappalardo R. G., J. Lum., 34, 133 (1985). 
10. Hintzen H. T., Baken J. M. E. and Bostelaar L. C. J. M., unpublished results.

11. Daly J. G., Schmidt J. A. and Gruber J. B., Phys. Rev., B27, 5250 (1983); Dexpert-Ghys J., Faucher M. and Caro P., Phys. Rev., B23, 607 (1981).

12. Linares C. and Gaume-Mahn F., C.R. Acad. Sci. Paris, 277, 431 (1973); Moune O. K., Porcher P. and Caro P., J. Solid State Chem., 50, 41 (1983).

13. Goodman B. A., Greenwood N. N. and Turner G. E., Chem. Phys. Lett., 5, 181(1970).

14. Shenoy G. K. and Dunlap B. D., Nucl, Instr. and Meth., 71, 285 (1969).

15. Glentworth P., Nichols A. L., Newton D. A., Large N. R. and Bullock R. J., J. Chem. Soc., Dalton Trans., 546 (1973).

16. Kalvius G. M., Klein U. F. and Wortmann G., J. Phvs. Coll., 35, C6-139 (1974).
17. Dulaney G. W. and Clifford A. F., Mössb. Eff. Meth., 5, 65 (1969)

18. Forest H. and Ban G., J. Electrochem. Soc., 118, 1999 (1971).

19. Pappalardo R. G. and Hunt R. B., Jr, J. Electrochem Soc., 132, 721 (1985).

20. Zolin V. F., Malova A. M., Markushev V. M. and Tsaryuk V. I., J. Appl. Spectr., 41, 1360 (1984); Tola P., Retournard A., Dexpert-Ghys J., Lemonnier M., Pagel M. and Goulon J., Chem. Phys., 78, 339 (1983).

21. Medhı O. K. und Agarwala U., Z. Naturforsch., 34a, 625 (1979).

22. Gerth G., Kienle P. and Luchner K., Phys. Lett., 27A, 557 (1968).

23. Deeney F. A., Delaney J. A. and Ruddy V. P., Phys. Lett., 27A, 571 (1968) 